\title{
TRIP PRODUCTION MODELING OF SELECTED ZONES IN BAGHDAD CITY
}

\author{
Miss Zainab Abd Alkareem \\ Salim ${ }^{1}$
}

* Dr. Gofran J. Qasim ${ }^{2}$

1) Highway and Transportation Eng. Dept., Engineering Collage, Mustansiriyh University, Baghdad, Iraq

2) Highway and Transportation Eng. Dept., Engineering Collage, Mustansiriyh University, Baghdad, Iraq

\begin{abstract}
The initiation of this analysis is to establish a mathematical model for predicting trip production for Hay Ur sector in Baghdad city that involving socioeconomic and land use features. To achieve the study objective, the study area is divided into five zones. The whole number of distributed forms is 720 . Two mechanisms were adopted, the entire conversation and home questionnaire form survey. The survey forms have been spread in intermediate schools, high schools and private institutes of education. Only 542 forms were received with the response rate is $75.28 \%$ for the study area. The collected forms have been processed and analyzed to qualify the socioeconomic features in each zone. The trip production models for five purposes of trips (Home base- work, education, shopping, other trips, and the total trips) have been developed. These models have been built when the gathered data was fed to the (SPSS) software version 22 by using stepwise regression process. Results show that total household trips are linked to family size and composition such as number of men, number of women, : number of persons less than 6 years, total household employees, total household pupils, dwelling unit area, dwelling unit and vehicle ownership.
\end{abstract}

Keywords: Trip production; Household trip, Linear Regression, SPSS software.

\section{Introduction}

The group of people or automobiles throughout time unit that could be expected to move on a given segment of a transportation network under a variety of land-use, social, economic, and environmental conditions is called travel demand. Forecasting of trip demand estimates the amount, kind and origin of "trips" (source and target) on a network of transport [1].

The problem of urban transport is the product of several interconnected factors. The tremendous population growth in urban areas and their real expansion as a result of population redistribution improved living standards due to increase income, and resulting increased reliance on private cars are just some of these factors [2].

It became necessary to prepare comprehensive researches of the areas to recognize the causes of these journeys then identify the source and target of these travels for determination of building statistical models to forecast the movement of these trips. In practice, constructing a mathematical relation according to field information is not easy since the reality is that many phenomena are non-linear and/or collinear, or a model is difficult to create.

\section{Literature Review}

*Corresponding Author: gofranqasim@uomustansiriyah.edu.iq 


\subsection{General}

The process of transportation planning depends on travel demand predicting, which includes estimating the impact of different policies and programs on travel in metropolitan areas. Detailed information is provided via the prediction process about travel demand forecasting which might contain vehicle numbers on a future freeway or traveller's numbers on a new bus service express [3].

The relationships of trip generation are mostly created by employing the linear regression analysis technique. Regression analysis helps to estimate one variable or the dependent variable from the other variable or the independent variable. In other words the value of one variable can be estimated, provided that the value of the other variable is given [4].

\subsection{Urban Transportation Planning Background}

Abdali and Qasim [5] developed models for AlAmarah City. The area of study is divided into five areas composed of 113 traffic analysis zones. The trip generation models for six purpose of the trip (Home base Work, educational, religious, social, shopping, other trips) were established by using (SPSS) program version 20 and using stepwise regression technique (Multiple Linear Regression, MLR). Results showed that: Gender, workers number in the household, number of students per household, and the ownership of vehicles represent the most significant independent variables that affect the total trip generation rate in Al-Amarah city. The coefficient of determination $\mathrm{R}^{2}$ for ( $\mathrm{Y}$ ) the number of total trips is 0.94 and it is considered as a very good relationship obtained

Al-Zubaidy [6] provided a prediction trip production models for Al-Diwaniyah city that includes the social economical features, using of alternative statistical techniques for trip generation modeling (MLR and the ANN). The (ANN) technique was applied to the collected data using Neuframe 4 software to develop a relationship between every day trips and socioeconomic factors in sector No.2. Results displayed that the model of trip generation is based on the size of family, sex, and the family workers and student's number.

Al-Zaidy [7] studied the impact of social economic variables on trip production for AlHadar region in Al-Dora section in the southern part of Baghdad city. The study established that workers number, student's number, vehicle type and age group between (21-40) were the most important independent variables on trip generation for families.

Al-Khalidy [8] attempted to find out a model to reveal the source of the transportation network in Al-Mahmoodiya land study, gravity force and the number of trip production. The study concluded that the power of attraction between these nearby rural areas and the city centre is higher than other remote cities. This reveals the weak connection and a link between the province center and its affiliated cities. Moreover, it maintains the increase in depending upon Al-Mohmoodiya district center.

Safa-Eldeen [9] developed a model of trip generation for Kirkuk city. Trip generation equation was predicted by using both multiple linear regression and cross-classification methods. Results displayed that, trip generation model depending on the size of family, area of a dwelling unit and the worker's number per family. Another model, representing the relationship between trip attraction between zones and the number of employment per zone was also established. 
Al-Hasani [10] developed relationships between daily trips and socioeconomic characteristics for the side of Al-Karkh in Baghdad city. The trip generation has been predicted by both multiple linear regression and cross-classification methods. Results indicated that the total individual traveling per household is related to the size of the family and composition variables like no. of persons more than 6 years old, no. of male, no. of workers male. Also, it is related to the number of available vehicles, type of dwelling unit. A model was developed with a determination coefficient $\left(\mathrm{R}^{2}\right)$ equal to 0.678 for the total area of study.

\section{Research Objectives}

The primary objective of the study is to define the travel pattern in the study area and to develop statistical models for trips production. The specific objectives are:

1- Obtain the accurate and detailed information on travel characteristics of household wherever possible in Hay Ur in Baghdad urban area.

2- Formulate statistical models using Multiple Linear Regression (MLR) technique to replicate the information on demography and socio- economic parameters.

\section{Research Methodology}

The data collection is very important and considered as one of the most difficult stages in the urban transportation process. It is required thorough investigation, extensive preparation, qualified interviewers, cost, and time as well as assistance from some governmental authorities. The work methodology for data collection should be accomplished with a sequence steps in order to avoid the bias [11]. The following steps are suitable to be followed:
1- The study area selection

2- The study area zoning

3- Preparing the form of the questionnaire sheet

4- The required samples calculation and selection

5- Data gathering and implementation

\subsection{Study Area Selection}

First of all, the area of research for which transport facilities are being built is limited; the imaginary line that defines the research area boundary called 'external cordon'. Region within this boundary line that essentially dictates the style of travel is subdivided into zones. The external cordon line selection for the study of urban transportation should be carried out carefully [11].

Baghdad is the largest city and capital of Republic of Iraq .It lies on the banks of the Tigris Rive,r which divide the city into two parts, AlRusafa on the left side of the river and Al-Karkh on the right side of it. It has special role among Iraqi cities for the following reasons:

1. It is a politician and administrative capital of Iraq

2. It has an ancient historical importance

3. Its central location gives importance to a considerable extent.

For all the above reasons, it plays as a center for commercial, business services, administrative, activity and, educational therefore, acts as the focal point for the national transport systems of Iraq. Fig. 1 presents the satellite Image of Baghdad city. 


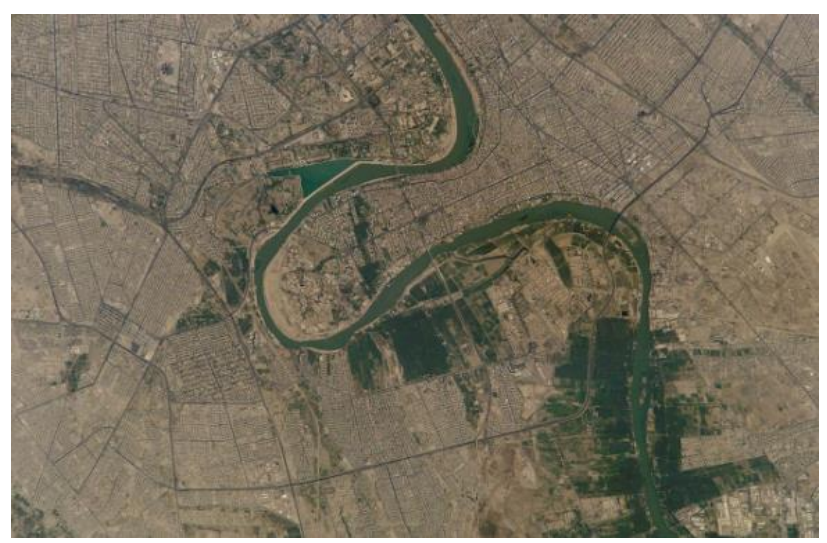

Figure 1. The Satellite Image of Baghdad City

Hay $\mathrm{Ur}$ is one of the main administrative districts affiliated to Baghdad province. Located on the right side of the Tigris River "Al-Rusafa" in the northeast of Baghdad, it is located $8 \mathrm{Km}$ from the center of the city, where it ends at the earth dam built on the police channel. Fig. 2 shows the councils municipal of Baghdad City.

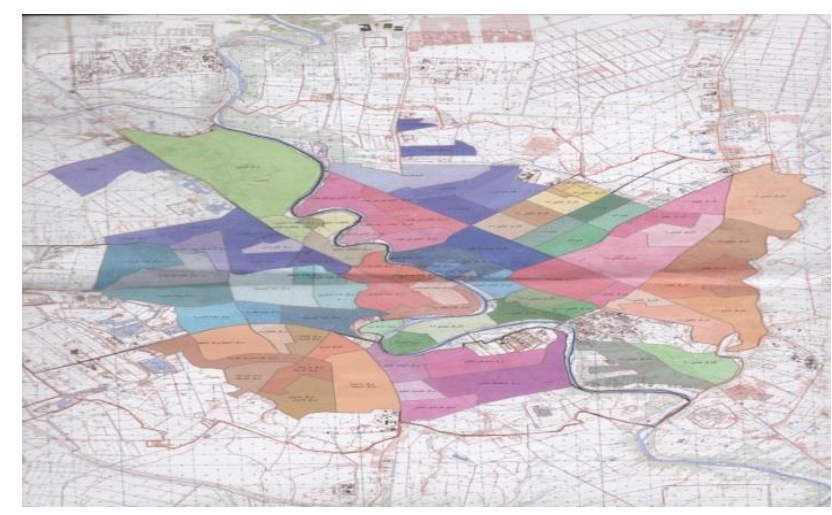

Figure 2. Councils Municipal of Baghdad City (Amanat Baghdad)

\subsection{Zoning the Study Area}

To simplify the aggregate of data in the process of transport planning, the research area is separated into a set of zones, subdivision into zones helps to geographically connect the source and target of the trip. Zones inside the external cordon of study area named internal zones and others called external zones [12].
Baghdad city is divided into 10 sectors. For the purposes of data collection and monitoring, each sector is split to a set of zones and hence the overall number of TAZs is forty-five. The zoning is dependent on the governmental partitions of council municipals. Area zoning is presented in Fig. 3.

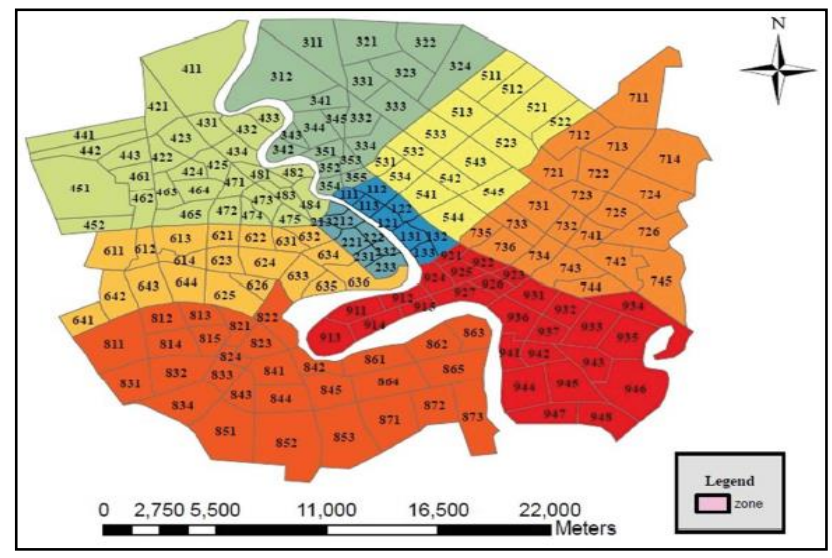

Figure 3. TAZs of Baghdad City [13].

In this study, the area of the study is divided into five zones $(325,327,329,341,345)$. The zoning is based on the administrative divisions of council municipals, with some additional divisions of council municipals (Hay Ur 1) consist of zone 325 and part of zone 327, (Hay Ur 2) consist of another part of zone 327 and part of zone 329, (Um Al-Kubr) consist of zone 341, 345 and another part of zone 329 as shown in the Fig. 4. The descriptions of the TAZs population and number of households are tabulated and shown in Table 1.

Table 1. TAZ Population and Households According to the Municipal Council

\begin{tabular}{ccc}
\hline $\begin{array}{c}\text { Traffic } \\
\text { Analysis Zone }\end{array}$ & $\begin{array}{c}\text { No. of } \\
\text { Households }\end{array}$ & Population \\
\hline 325 & 7000 & 46500 \\
327 & 5000 & 32250 \\
329 & 4700 & 28500 \\
345 & 6000 & 38650 \\
341 & 2500 & 15750 \\
Total & 25200 & 161650 \\
\hline
\end{tabular}

\subsubsection{Zones coding}




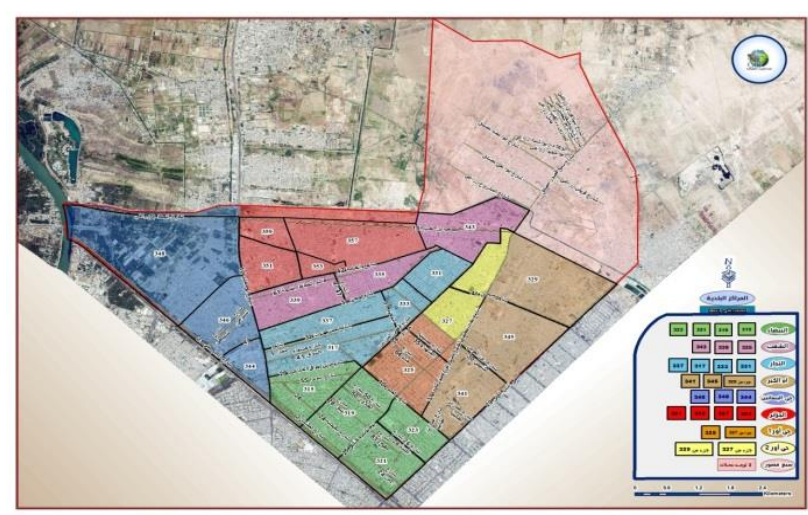

Figure 4. TAZs of the Study Area According to the Municipality Divisions.

\subsubsection{Sample size}

The necessary sample size to be questioned is based on the entire population residing within the research area. Population and households are possessed from the study area's Municipal Council for correctness. There are (161650) residents in the selected study area and the whole number of households are (25200). Since it is not practical to collect the data from the entire population of the study area, therefore it became necessary to calculate the sample size according to the population density of the study area. Table 2 represents the minimum and recommended values for sample size [14].

Table 2. Sample Size for Home Interview Survey [14].

\begin{tabular}{ccc}
\hline \multirow{2}{*}{$\begin{array}{c}\text { Population of } \\
\text { study area }\end{array}$} & \multicolumn{2}{c}{ Sample Size } \\
\cline { 2 - 3 } Under 50,000 & 1 in 10 & Recommended \\
$50000-150000$ & 1 in 20 & 1 in 5 \\
$150000-300000$ & 1 in 35 & 1 in 8 \\
$300000-500000$ & 1 in 50 & 1 in 15 \\
$500000-1$, & 1 in 70 & 1 in 20 \\
000,000 & 1 in 100 & 1 in 25 \\
Over 1 million &
\end{tabular}

According to the Table 2, the population of the research area is within the range of (150000 300000). Therefore the minimum value for the calculating of the sample size is $1: 35$.

The size of the study area sample = $(1 / 35) * 25200=720$ questionnaire forms will be distributed for data collection.
The criteria of the distribution of full interview and questionnaire techniques for all traffic analysis zones in the study area are dependent on the number of households in each zone. Table 3 presents the survey types method distribution.

Table 2. Survey Types Method Distribution.

\begin{tabular}{ccccccc}
\hline \multirow{2}{*}{ TAZ } & \multicolumn{2}{c}{ Full Interview } & \multicolumn{2}{c}{ Questionnaire } & \multicolumn{2}{c}{ Total } \\
\cline { 2 - 7 } & No. & $\%$ & No. & $\%$ & No. & $\%$ \\
\hline 325 & 50 & 25.0 & 150 & 75.0 & 200 & 100 \\
327 & 30 & 20.98 & 113 & 79.02 & 143 & 100 \\
329 & 20 & 14.93 & 114 & 85.07 & 134 & 100 \\
345 & 45 & 26.32 & 126 & 73.68 & 171 & 100 \\
341 & 10 & 13.89 & 62 & 86.11 & 72 & 100 \\
Total & 155 & 21.53 & 565 & 78.47 & 720 & 100 \\
\hline
\end{tabular}

A preliminary analysis of the results obtained from field survey has been implemented before model building. The results may help in the decision making later in model development. From Fig. 5 the age group (6-18) and (19-24) which represents primary, intermediate school, colleges and institute groups are higher than other groups in all zones and this leads to increase the rates of educational trips. The work trips come in the second stage than the shopping and the other trips as shown in the Fig. 6.

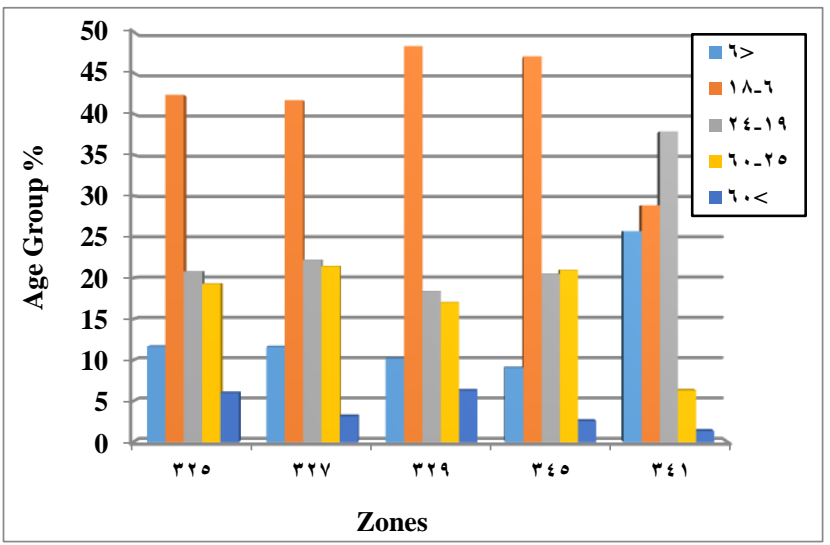

Figure 5 Distribution of Age Group in all TAZs 


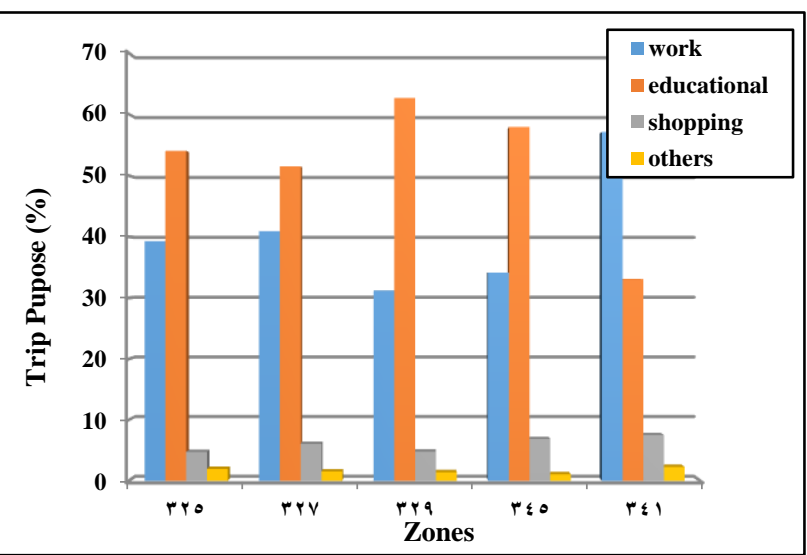

Figure 6 Types of Trip Purpose in TAZ

\section{Household Trip Production Model}

Multiple linear Regression (MLR) technique will be adopted to derive trip production model which assumes a relation of the numbers of travels produced (dependent variable) with the socioeconomic features (independent variable) in the selected zone.

These are the criteria for achieving typical regression models:

- High intercorrelation doesn't exist among predicted variables.

- Data do not include significant discoveries or outliers.

- Error distribution is normal.

- Errors have a continuous variance $\sigma^{2}$ (Homoscedasticity Hypothesis).

- The errors distribution mean is equal to zero.

The symbols of the variables taken into account in the analysis are expressed as follows:

\section{1- Dependent Variables}

- Y : Daily Household overall trips.

- $\mathrm{Y}_{1}$ : Family work trips per day.

- $\mathrm{Y}_{2}$ : Family educational trips per day.

- $Y_{3}$ : Family shopping trips per day.

- $\mathrm{Y}_{4}$ : Family other trips per day.

\section{2- Independent Variables}

- $\mathrm{X}_{1}$ :Family size (No.).

- $\mathrm{X}_{2}$ : Family males number (No.).

- $\mathrm{X}_{3}$ : Family females number (No.).

- $\mathrm{X}_{4}$ : Family workers number (No.).

- $\mathrm{X}_{5}$ : Family students number (No.).

- $\mathrm{X}_{6}$ : Family individual's number who age less than 6 (No.).

- $\mathrm{X}_{7}$ : Family individual's number greater than 60 years (No.).

- $\mathrm{X}_{8}$ : Household monthly income $(1,2,3)$.

- $\mathrm{X}_{9}$ : Area of the dwelling unit in $\mathrm{m}^{2}(1,2,3)$.

- $\mathrm{X}_{10}$ : Dwelling unit ownership (own, rented) $(1,2)$.

- $\mathrm{X}_{11}$ : Dwelling unit type (house, apartment) $(1,2)$.

- $\mathrm{X}_{12}$ : ownership of the Car (No.).

SPSS program ver. 22 is used in the correlation matrix calculation for the independent data collection variables as represented in Table 4.

\subsection{Multiple Linear Regression Model Development}

Trip production multiple linear regression models are established by using the SPSS software version 22, the available linear regression methods are as follows:

- Enter

- Stepwise

- Remove

- Backward

- Forward

The stepwise method is the preferable and usually the method that is applied to derive a simple prediction regression models for each independent variable [15]. 
Table 4. MultiCollinearity Matrix of Independent Variables

\begin{tabular}{ccccccccccccc}
\hline Variables & $\mathbf{X}_{\mathbf{1}}$ & $\mathbf{X}_{\mathbf{2}}$ & $\mathbf{X}_{\mathbf{3}}$ & $\mathbf{X}_{\mathbf{4}}$ & $\mathbf{X}_{\mathbf{5}}$ & $\mathbf{X}_{\mathbf{6}}$ & $\mathbf{X}_{\mathbf{7}}$ & $\mathbf{X}_{\mathbf{8}}$ & $\mathbf{X}_{\mathbf{9}}$ & $\mathbf{X}_{\mathbf{1 0}}$ & $\mathbf{X}_{\mathbf{1 1}}$ & $\mathbf{X}_{\mathbf{1 2}}$ \\
$\mathbf{X}_{\mathbf{1}}$ & 1.000 & & & & & & & & & & & \\
$\mathbf{X}_{\mathbf{2}}$ & .486 & 1.000 & & & & & & & & & & \\
$\mathbf{X}_{\mathbf{3}}$ & .542 & .252 & 1.000 & & & & & & & & & \\
$\mathbf{X}_{\mathbf{4}}$ & .144 & .337 & .033 & 1.000 & & & & & & & & \\
$\mathbf{X}_{\mathbf{5}}$ & .556 & .497 & .632 & -.167 & 1.000 & & & & & & & \\
$\mathbf{X}_{\mathbf{6}}$ & .306 & -.011 & -.090 & .023 & -.167 & 1.000 & & & & & & \\
$\mathbf{X}_{\mathbf{7}}$ & .352 & .207 & .110 & .072 & .023 & .100 & 1.000 & & & & & \\
$\mathbf{X}_{\mathbf{8}}$ & .103 & .177 & .050 & .380 & .016 & .031 & .050 & 1.000 & & & & \\
$\mathbf{X}_{\mathbf{9}}$ & .216 & .188 & .096 & .196 & .113 & -.035 & .037 & .234 & 1.000 & & & \\
$\mathbf{X}_{\mathbf{1 0}}$ & -.170 & -.247 & -.041 & -.146 & -.096 & -.037 & -.060 & -.083 & -.233 & 1.000 & & \\
$\mathbf{X}_{\mathbf{1 1}}$ & -.163 & -.149 & -.114 & -.021 & -.109 & -.004 & -.007 & -.009 & -.132 & .412 & 1.000 & \\
$\mathbf{X}_{\mathbf{1 2}}$ & .091 & .132 & -.010 & .323 & -.061 & .183 & .128 & .247 & .191 & -.068 & -.018 & 1.000 \\
\hline
\end{tabular}

The independent variable with the highest F-test is selected as the main variables inserted. The procedure is continued if at least one variable surpasses the standard. The method takes into account if the model will be enhanced through a second independent variable was added, etc. These checks whole variables to decide which of them has the F-value test and which matches the F-test chosen for inter criteria. Either probability of $\mathrm{F}$ value test or of $\mathrm{F}$ value test is used as inter criteria. In the analysis, $\mathrm{F}$ is used as a Probability equal to 0.05 ; this corresponds to a value $\mathrm{F}$ test of 3.48 [16].

The autonomous variables descriptive statistics that are used in the developing of trip production modes are presented in the Table 5. The stepwise regression models at 0.95 selected confidence levels are summarized in Table 6.
Table 5. Independent Variables Descriptive Statistics

\begin{tabular}{lccc}
\hline Variable & Mean & Std. Deviation & N \\
\hline Family size & 6.5125 & 1.99620 & 400 \\
No. of Males & 2.5725 & 1.16754 & 400 \\
No. of Females & 2.8550 & 1.32225 & 400 \\
Workers & 1.4275 & 0.79771 & 400 \\
Students & 2.8300 & 1.48209 & 400 \\
Persons less than 6 & 0.7725 & 0.92622 & 400 \\
Persons more than & 0.2750 & 0.65226 & 400 \\
60 & 1.7850 & 0.65944 & 400 \\
HH Income & 1.5625 & 0.52610 & 400 \\
Dwelling unit Area & 1.1075 & 0.31014 & 400 \\
Dwelling unit owner & 1.0300 & 0.17080 & 400 \\
Dwelling unit type & 0.7350 & 0.66399 & 400 \\
No. of cars owner & &
\end{tabular}

Table 6. Stepwise Regression Models Parameters of All Production Trips Types

\begin{tabular}{ccccc}
\hline Trip Type & Model & $\mathbf{R}^{2}$ & Adj R $^{2}$ & S.E.E \\
\hline Work Trip & $0.102+1.767 \mathrm{X}_{4}+0.137 \mathrm{X}_{12}$ & 0.877 & 0.876 & 0.541 \\
Educational Trip & $-1.452+1.887 \mathrm{X}_{5}-0.045 \mathrm{X}_{1}+0.134 \mathrm{X}_{10}+0.051 \mathrm{X}_{6}$ & 0.978 & 0.978 & 0.410 \\
Shopping Trip & $2.014+0.268 \mathrm{X}_{1}+0.304 \mathrm{X}_{4}+0.071 \mathrm{X}_{9}-0.119 \mathrm{X}_{10}$ & 0.862 & 0.861 & 0.355 \\
Other Trip & $-0.921+0.977 \mathrm{X}_{2}+0.505 \mathrm{X}_{7}+0.240 \mathrm{X}_{12}$ & 0.988 & 0.988 & 0.143
\end{tabular}




\section{Validation of Models}

The final stage of the model building method is the validation of the developed model; it is purely a series of comparisons. Comparing the model implemented in the base year with surveyed data helps to demonstrate how the developed model replicates the current travel patterns. A series of validation tests were carried out on the model parts at each phase of the development of the travel model process following the model parameters estimation (coefficients, constants) of the ability of the model to accurately simulate the actual travel behavior [17].

The calibration sample is $(75 \%)$ of the original data will be used to construct the models and the remaining $(25 \%)$ will be used for validation processes for each trip type. That is the strictly random split, and the data are not duplicated [18].

Fig. 7 through Fig. 11 shows the resulting plots between observed and predicted (Y) values for work, educational, shopping, other, and total trips respectively.

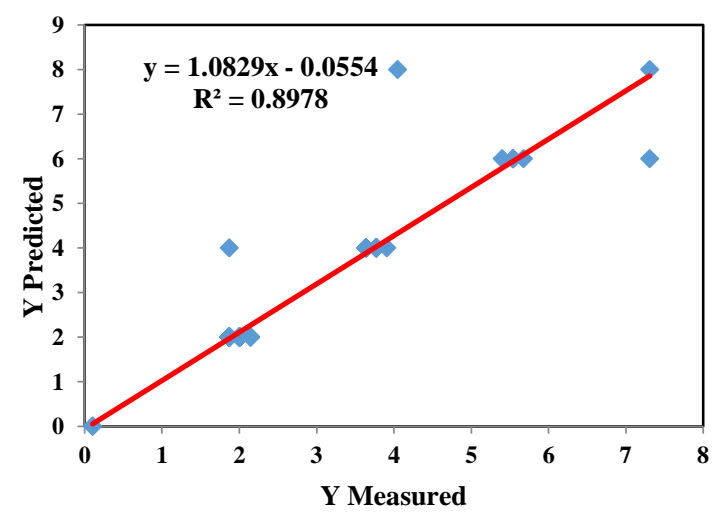

Figure 7. Observed Trip Rate versus Regression Trip Rate of work Trip

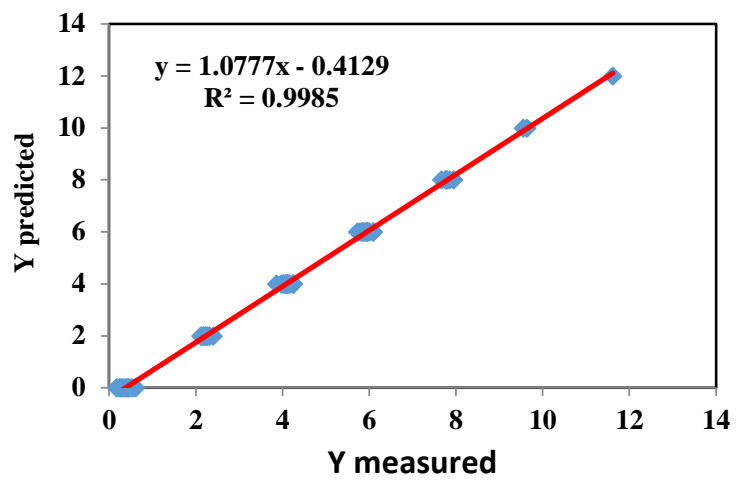

Figure 8. Observed Trip Rate versus Regression Trip Rate of educational Trip

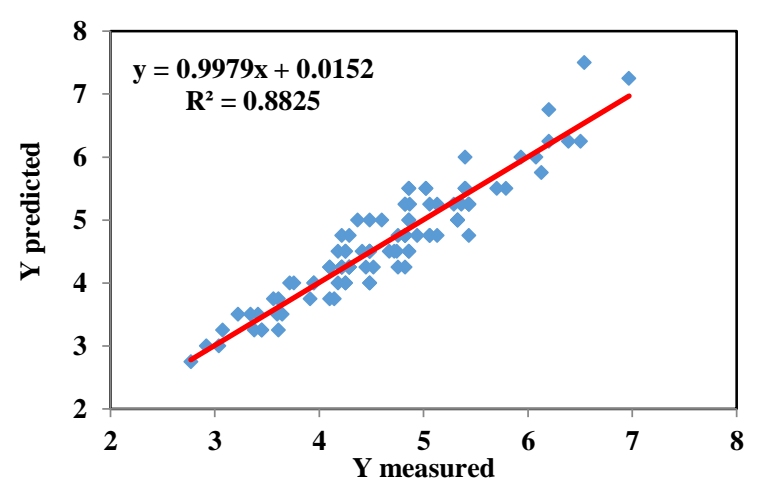

Figure 9. Observed Trip Rate versus Regression Trip Rate of shopping Trip

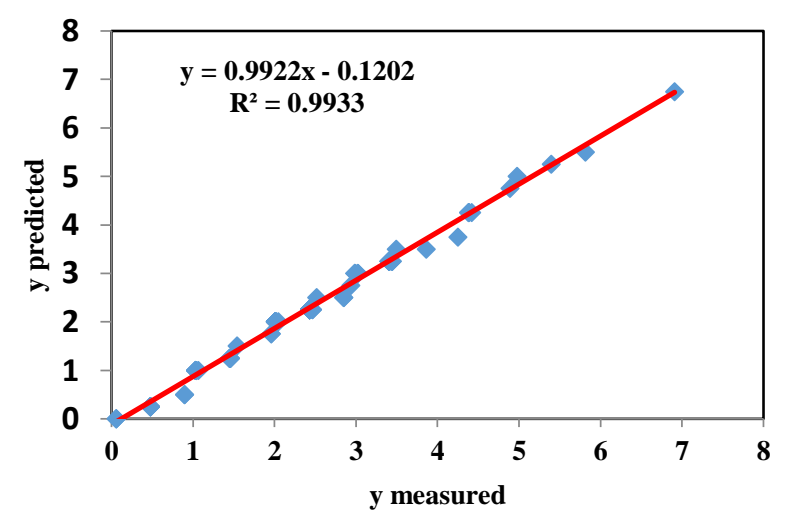

Figure 10. Observed Trip Rate versus Regression Trip Rate of other Trip 


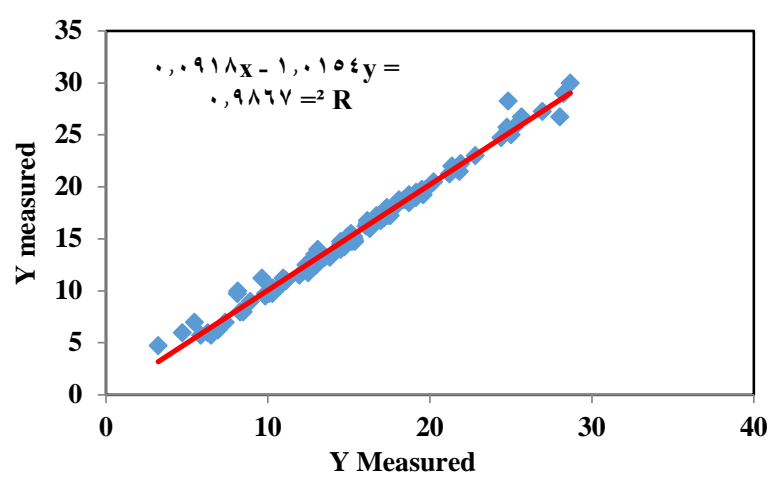

Figure 11. Observed Trip Rate versus Regression Trip Rate of total Trip

\section{Conclusions}

1- The age group (6-18) and (19-24) which represents primary, intermediate school, colleges and institute groups are higher than other groups in all zones and this leads to increase the rates of educational trips. The work trips come in the second stage than the shopping and the other trips.

2- Huge number of primary, intermediate and secondary schools that is inside the suburban zones and nearby the dwelling units. This leads to educational trips that range from 5 to 10 minutes on short walks

3- In the educational trips, the number of students in the family is the most effective parameter then dwelling unit ownership and number of individuals less than 6 years while the family size parameter has a negative effect on these trips.

4- Work trips have a substantial proportion of the whole trips and these trips are related to the number of employees per household and age group (25-60).

5- The number of workers in the family and the number of car owner represents the most effective independent variables that affect the work trips.
6- In the shopping trips, the family size and number of workers in the household represent the most effective independent variable then the area of dwelling unit parameter.

7- Other production trips are more influenced by the number of males in the household than by the number of females due to social factors in the city, then the number of individuals over 60 years and the number of car owners.

8- The main independent factors that influence the total trip production percentage in the study area are the number of males, number of students, number of workers, number of persons greater than 60 years, the number of car owner, and the family size.

9- The relationship between the mode of transportation used and monthly household income is important. Families with high monthly incomes have a propensity to use private vehicles; whereas families with low monthly incomes prefer to use public transport.

\section{Acknowledgements}

The authors are grateful to the Mustansiriyah University, College of Engineering, Highway and Transportation Department for their support and help to accomplish this work contained in this study.

This research did not receive any specific grant from funding agencies in the public, commercial, or not-for-profit sectors.

\section{Conflict of interest}

The authors confirm that the publication of this article cause no conflict of interest. 


\section{References}

1. Garber, N.J., Hoel, L.A., 2010,"Traffic and Highway Engineering ", $4^{\text {th }}$ Edition, International Student Edition, Thomson, USA.

2. National Transportation Library, "Travel Model Development and Refinement-trip Generation" Final Report, US Department of Transportation Research and Innovative Technology Administration, 2006.

3. Federal Highway Administration (Urban Mass Transportation),2010" An Introduction to Urban Travel Demand Forecasting", National Transportation Library, spreading on (http://ntl.bts.gov/DOCS/ut.html)).

4. Khan I. I., Khanum A., "Fundamentals of Biostatistics" India, 3rd Edition, 2008.

5. Abedali A.H., Qasim G.J." Trip Production Modeling for Selected Zone in AL-Amarah City" 1st International Conference on Engineering and Innovative Technology, SU-ICEIT 2016, April 12-14, 2016, Salahaddin University-Erbil, Kurdistan, Iraq

6. Al-Zubaidy H. A. N., 2011,'Trip Generation Modeling For Selected Zones In Al-Dywania City",MSC Thesis Submitted to the Highway and Transportation Engineering Department College of Engineering /Al- Mustansiriya University.

7. Al-Zaidy M.A., 2005, "Influence of Socio-Economic Factors on Trip Generation of a Selected District in Baghdad", MSc thesis submitted to the Engineering College, University of Baghdad.

8. Al-Khalidy H. A. A. 2005, " Evaluating the Efficiency of the Transportation Net in Al-Mahmoodiya Land: Study of Gravity force and the Number of Trip generation" MSc. thesis submitted to the Engineering College, University of Baghdad.

9. Safa-Eldeen G.I., 2006, "Trip Generation Model for Kirkuk City", MSc thesis submitted to the, Building and Construction Engineering, University of Technology.

10. Al-Hasani S.S.F., 2010, "Modeling Household Trip Generation at Discreet Zone in Baghdad City" MSc. thesis submitted to the Engineering College, University of Baghdad.

11. Qasim, G. J. (2016) . Travel Demand Modeling: Al-Amarah City as a Case Study". PhD. thesis submitted to the Engineering College, University of Baghdad.

12. Kadiyali, 2009, "Traffic Engineering and Transportation Planning". 7th Edition Khanna publisher.

13. Asmael N.M., 2015 "A GIS-Assisted Optimal Route Selection Based on Transportation Network Design (Baghdad Metro Case Study". PhD. thesis submitted to the Engineering College, University of Baghdad.

14. R. J. Salter, 1989, "Highway Traffic Analysis and Design" 2nd edition, copyright Holder Macmillan UK Publishers Limited.

15. Carmer D.; Howitt D.,2004, "The SAGA Dictionary of Statistics".

16. Meyer, L.S., (1975), "Data Analysis for Scientists and Engineers." 2nd Edition, John Wiley and Sons, Inc., New York.

17. Mathew, T. V and Rao, K. V. 2007, "Introduction to Transportation Engineering - Travel Demand Modeling”. National Programming on 
Technology Enhanced Learning (NPTEL).

18. Giancristofaro R. A., L. Salmaso,2, 2003,"Model Performance Analysis and Model Validation in Logistic Regression",Statistica, anno LXIII, n. 